\title{
Domiciliary ventilation in chronic obstructive lung disease
}

Improvement in the understanding of the basic mechanisms of disease should lead to the development of new and better treatments. Sometimes the initial rationale for such treatment changes, and this appears to be the case with the relatively new technique of intermittent positive pressure ventilation, technical aspects of which have recently been reviewed. ${ }^{1}$

\section{Respiratory muscle fatigue}

A major stimulus to the development of domiciliary ventilation was the report in 1977 that the diaphragm, like other skeletal muscle, could be made to fatigue-that is, fail to sustain the desired or expected force. ${ }^{2}$ Since then a host of publications (reviewed in refs 3-5) have defined the biochemical and physiological determinants of fatigue. Several tests have been developed to measure impending or established failure of respiratory muscle force generation..$^{6-10}$ These assess either the altered activation or relaxation of the respiratory muscles during voluntary contractions $s^{6-8}$ or the ability of the muscle to respond to external electrical stimulation, usually via the phrenic nerve. ${ }^{910}$ The power spectrum of the electromyogram of respiratory muscle changes as fatigue develops, a relatively greater contribution being made from the lower frequencies. This fall in the ratio of power in the high to the low frequency bands ( $\mathrm{H}: \mathrm{L}$ ratio) was one of the first objective measure of respiratory muscle fatigue. ${ }^{6}$ Others have used the slowing of muscle relaxation that occurs as fatigue develops ${ }^{7}$ or the failure to develop high initial driving pressures during loading. ${ }^{8}$ Studies of the force developed after phrenic nerve stimulation by trains of impulses of differing frequency ${ }^{9}$ or during relaxation or voluntary activation of muscle ${ }^{10}$ have been advocated as more objective tests of the force generating capacity of these muscles. Bellemare and Grassino developed the concept of the tension-time index of the diaphragm (TTdi) as an indirect measure of respiratory muscle energy consumption. ${ }^{11}$ They found that when the duration of inspiration ( $\mathrm{Ti}$ ) expressed as a percentage of the total respiratory duty cycle ( $\mathrm{Ti} / \mathrm{Ttot}$ ) is multiplied by the pressure developed (Pdi) as a percentage of the maximum static pressure (Pdimax) a constant resulted $(\mathrm{TTdi}=\mathrm{Ti} / \mathrm{T}$ tot $\times \mathrm{Pdi} / \mathrm{Pdimax})$. These workers found empirically that when this constant exceeded 0.15 respiratory muscle fatigue, as assessed by electromyographic criteria and endurance time, would always develop. They showed that the force reserve of the diaphragm is smaller in patients with severe chronic obstructive lung disease and hence the risk of developing fatigue is greater. ${ }^{12}$

Surprisingly, there is a paucity of data confirming the presence of diaphragmatic fatigue in acute clinical conditions but serial observations of the $H: L$ ratio showed that this occurred in six of 12 patients during trials of weaning from assisted ventilation. ${ }^{13}$ Patients with electromyographic fatigue had a rapid, shallow breathing pattern and developed paradoxical rib cage movements during inspiration. The finding that similar breathing patterns occur during unfatiguing loading ${ }^{14}$ has cast doubt on the general usefulness of these signs. Early reports suggested that respiratory muscle fatigue was an important mechanism of dyspnoea in such patients ${ }^{15}$ but subsequent investigation makes this unlikely. ${ }^{16}$

Several different forms of respiratory muscle fatigue have been described, depending on which part of the activation pathway of muscle contraction from the cerebral cortex to intracellular calcium release has been disturbed. ${ }^{17}$ Failure to generate force at high frequency (high frequency fatigue) is short lived and probably not relevant to normal physiology as the stimulation frequencies exceed those seen in vivo. Low frequency fatigue is more sustained and may occur at levels that might be seen in life. Central fatigue appears to be a protective mechanism whereby the muscle reduces the central neuronal firing frequency by some poorly understood mechanism but still retains the capacity to respond to direct stimulation. Each of these must be distinguished from failure to activate the muscle for behavioural reasons, which may prove to be the most important mechanism of all. Tests such as the $\mathrm{H}: \mathrm{L}$ ratio reflect short lived changes in membrane potential due to high frequency stimulation rather than a longer term reduction in force generation due to loss of contractile function, as occurs after low frequency stimulation. ${ }^{18}$ The possibility of persistent functional loss led to speculation that chronic hypoventilation was a result of this low frequency fatigue. ${ }^{19}$ As muscle rest allows low frequency fatigue to recover, a feature so characteristic that it is now included in one of the recently proposed definitions of fatigue ${ }^{5}$ it followed that respiratory muscle rest in the form of assisted ventilation would relieve chronic fatigue and produce a sustained correction of hypercapnia. Because hypercapnia itself further impairs respiratory muscle function $^{20}$ its correction might break a vicious circle perpetuating the fatiguing process.

\section{Intermittent negative pressure ventilation in chronic obstructive lung disease}

Before this theoretical rationale was developed some clinicians had experience of domiciliary ventilation in patients with chronic respiratory failure who were capable of spontaneous ventilation by day. A few patients with kyphoscoliosis, both young ${ }^{21}$ and old, ${ }^{22}$ or a previous thoracoplasty ${ }^{23}$ could be kept at home with a more normal daytime arterial carbon dioxide tension $\left(\mathrm{PaCO}_{2}\right)$ produced by regular night time negative pressure ventilation. When this treatment was given to hypercapnic patients with chronic obstructive lung disease in an open, uncontrolled trial, dramatic improvements in daytime $\mathrm{PaCO}_{2}$ and, more importantly, in inspiratory muscle pressures occurred. ${ }^{24}$ The latter finding suggested that treatment was reversing inspiratory muscle fatigue and led several groups to test this form of treatment $\mathrm{t}^{25-30}$ (table). The duration and frequency, the period of follow up, and the measures of outcome varied between the trials but a consistent pattern of improvement was seen in patients with substantial hypercapnia while little if any change occurred in relatively normocapnic patients with airflow limitation.

The implications of successful treatment for such a common problem led the National Heart, Lung, and Blood Institute in the United States to set up a controlled trial of respiratory muscle rest by Cuirass respirator, the design of which has recently been reported. ${ }^{31}$ The patients studied had stable chronic obstructive lung disease, a forced expiratory volume in one second below $50 \%$ predicted, and an $\mathrm{FEV}_{1}$ /forced vital capacity (FVC) ratio below $60 \%$ as well as grade 4 breathlessness (on the basis of the American Thoracic Society criteria). Most were normocapnic and received ventilation by day, though precise details of the duration of treatment are not yet available. Care was taken to ensure that ventilatory synchrony was obtained and intrinsic respiratory muscle activity was suppressed to ensure that the respiratory muscles were rested. ${ }^{32}$ Although the results have not been formally published, preliminary 
Published results of intermittent negative pressure ventilation in chronic obstructive lung disease

\begin{tabular}{|c|c|c|c|c|c|c|c|c|c|c|c|}
\hline \multirow[b]{3}{*}{ Reference } & \multicolumn{2}{|l|}{ Number ${ }^{\star}$} & \multirow{3}{*}{$\begin{array}{l}\text { Treatment } \\
\text { allocation }\end{array}$} & \multirow[b]{3}{*}{ Treatment } & \multirow{3}{*}{$\begin{array}{l}\text { Follow } \\
\text { up }\end{array}$} & \multirow{3}{*}{$\begin{array}{l}F E V_{1} \\
(l) \dagger\end{array}$} & \multirow{2}{*}{\multicolumn{2}{|c|}{$\mathrm{PaCO}_{2}(\mathrm{kPa})$}} & \multirow{2}{*}{\multicolumn{2}{|c|}{$\mathrm{MIP}\left(\mathrm{cm} \mathrm{H} \mathrm{H}_{2} \mathrm{O}+\right)$}} & \multirow{3}{*}{ Comment } \\
\hline & \multirow{2}{*}{$\begin{array}{l}\text { Starting } \\
\text { study }\end{array}$} & \multirow{2}{*}{$\begin{array}{l}\text { Completing } \\
\text { study }\end{array}$} & & & & & & & & & \\
\hline & & & & & & & Initial & Final & Initial & Final & \\
\hline $\begin{array}{l}\text { Braun and } \\
\text { Marino }\end{array}$ & 18 & 18 & Open & $\begin{array}{l}\text { 4-10 h } \\
\text { daily }\end{array}$ & 5 months & - & $7 \cdot 2$ & $6 \cdot 0$ & $36 \%$ & $58 \%$ & Hospitalisation reduced \\
\hline $\begin{array}{l}\text { Cropp and } \\
\text { di Marco }\end{array}$ & $15(8)$ & $15(8)$ & Randomised & $\begin{array}{l}3-6 \mathrm{~h} \\
\text { daily }\end{array}$ & 3 days & $0 \cdot 8$ & $8 \cdot 0$ & 6.9 & 67 & 77 & $\begin{array}{l}\text { Sustainable ventilation } \\
\text { increased }\end{array}$ \\
\hline $\begin{array}{l}\text { Guttierrez } \\
\text { et } a l^{6}\end{array}$ & 5 & 5 & Open & $\begin{array}{l}8 \mathrm{~h} \text { once } \\
\text { weekly }\end{array}$ & 4 months & $27 \%$ & $7 \cdot 8$ & $6 \cdot 8$ & 45 & 62 & $\begin{array}{l}\text { Slower, deeper } \\
\text { breathing pattern }\end{array}$ \\
\hline $\begin{array}{l}\text { Zibrak } \\
\text { et a } P^{7}\end{array}$ & 20 & 9 & Crossover & $\begin{array}{l}2-6 \mathrm{~h} \\
\text { daily }\end{array}$ & $\begin{array}{l}6 \text { months } \\
\text { active }\end{array}$ & 0.55 & $6 \cdot 3$ & $6 \cdot 7$ & 30 & 30 & High dropout rate \\
\hline $\begin{array}{l}\text { Celli } \\
\text { et } a l^{28}\end{array}$ & $16(9)$ & $14(8)$ & Randomised & $\begin{array}{r}\text { 3-11 h } \\
\text { daily }\end{array}$ & 3 weeks & 0.60 & $6 \cdot 0$ & $5 \cdot 6$ & - & - & $\begin{array}{l}\text { Training improved exercise } \\
\text { tolerance in both groups }\end{array}$ \\
\hline Ambrosina & $18(10)$ & $18(10)$ & Randomised & $6 \mathrm{~h}$ daily & 5 days & $0 \cdot 77$ & $7 \cdot 5$ & $6 \cdot 8$ & 34 & 42 & 12 minute walk improved \\
\hline Scano et alo & $11(6)$ & $11(6)$ & Randomised & 4 h daily & 7 days & $28 \%$ & 8.0 & $6 \cdot 8$ & 41 & 45 & $\begin{array}{l}\text { Slower, deeper breathing } \\
\text { pattern }\end{array}$ \\
\hline
\end{tabular}

*Numbers actively treated in parentheses.

†Except where “\%," meaning "\% predicted," appears.

presentations in Europe and North America by the senior investigators indicate that no difference in any functional or mortality related variable was seen among the 184 patients randomised for treatment with active or sham ventilation. Even more recently, evidence has been presented showing that the diaphragm of patients with normocapnic chronic obstructive lung disease is capable of developing pressures similar to those of normal individuals, with no evidence of chronic fatigue. ${ }^{33}$

\section{Intermittent positive pressure ventilation in chronic obstructive lung disease}

A major difference between the studies at the National Heart, Lung, and Blood Institute on patients with chronic obstructive lung disease and those on patients with chest wall disorders is that the latter patients received overnight ventilation, which was not tolerated by the patients with chronic obstructive lung disease. Negative pressure ventilation by tank respirator, Cuirass shell, or pneumosuit is cumbersome and often uncomfortable because of the fixed body position. It may also induce upper airway obstruction during sleep and hence a sleep apnoea syndrome. ${ }^{34} \mathrm{~A}$ major advance came when Ellis and colleagues showed that nasal intermittent positive pressure ventilation was possible in patients with neuromuscular disease. ${ }^{35}$ The mechanism of sleep related oxygen desaturation in neuromuscular disease is different from that in chronic obstructive lung disease. ${ }^{36}$ Nevertheless, a study in four patients with chronic obstructive lung disease and six with restrictive disorders confirmed that increases in oxygen tension and falls in carbon dioxide tension could be produced with nasal intermittent positive pressure ventilation $^{37}$ and patients almost invariably preferred it to the negative pressure respirator when treatment was required for less than eight hours a day. If respiratory muscle rest is achieved in this way, can it influence blood gas tensions and general wellbeing favourably in patients with chronic obstructive lung disease?

This problem is addressed in a study reported in this issue of Thorax, ${ }^{38}$ where 12 patients with severe chronic obstructive lung disease (mean $\mathrm{FEV}_{1} 0.6 \mathrm{l}$, mean $\mathrm{PaCO}_{2} 7 \cdot 7$ $(\mathrm{SD} 0.9) \mathrm{kPa}$ ) and cor pulmonale were treated in an open study of nasal intermittent positive pressure ventilation. After six months' treatment eight patients were still using their ventilator and at one year seven patients. Small but significant changes in daytime blood gas tensions occurred in those using nocturnal ventilation, which raised nocturnal oxygen saturation and increased the total time slept above the baseline level. Self reported quality of life scores were unchanged but no data on exercise perfor- mance are presented here. These authors did not find a relation between changes in inspiratory muscle strength and $\mathrm{PaCO}_{2}$ in a previous report based on this group of patients. ${ }^{39}$ Some mechanical improvements were seen with a fall in residual volume and increased ventilatory response to hypercapnia after nasal ventilation. Unfortunately, in the paper presented in this issue ${ }^{38}$ there is neither a placebo limb nor a control group and comparative data about sleep quality are not available for the patients who dropped out of the trial. In addition, two of the patients followed up were apparently not stable initially, which raises some concern about the likely size of the therapeutic benefit. This technique is clearly feasible in the long term but is it better than current treatment with domiciliary oxygen?

\section{The future: problems and prospects}

It is much easier to emphasise the limitations of data such as these than conduct this type of taxing clinical investigation. This topic is of increasing importance in North America and Europe, 31 papers about it being presented at the last meeting of the American Thoracic Society. ${ }^{40}$ The financial implications of the widespread introduction of this treatment are considerable. Domiciliary ventilators currently cost about $£ 3500$ and substantial support is needed from doctors, physiotherapists, and nurses. What must future trials do to convince the sceptics that this is money well spent?

Further trials of negative pressure ventilation are unlikely, given the lack of success in the Montreal study and the present report that long term nasal intermittent positive pressure ventilation is feasible in patients with chronic obstructive lung disease. Future trials must be large enough to escape the potential for type II errors, which have affected all currently published studies. They should offer an "intention to treat" analysis to include the dropouts as well as the survivors and should contain a control group randomly allocated to sham treatment or possibly long term oxygen therapy. Clear outcome measures, both functional and psychological, must be chosen and applied in a way that takes account of the extent to which they are known to be affected by practice. On present evidence hypercapnic patients benefit most but many of these would normally receive domiciliary oxygen. Assisted ventilation may, however, permit better oxygenation than would otherwise occur for a given level of respiratory acidosis and here may lie its greatest promise. Studies of sleep quality during oxygen therapy and during nasal intermittent positive pressure ventilation must be undertaken as improved oxygenation alone may improve sleep..$^{41}$ Finally, further studies are urgently needed to determine which 
ventilator system is most effective and whether there are real differences between pressure and volume cycled respirators.

Many physicians prefer drugs to devices and are more likely to accept a treatment based on accepted theory. At present the theoretical basis for nocturnal ventilation appears uncertain but the practical evidence in its favour, though imperfect and fragmentary, is growing. The history of domiciliary oxygen treatment holds some hope for the enthusiastic supporter of nocturnal ventilation. Small studies with encouraging but inconclusive results ${ }^{42}{ }^{43}$ led to definitive investigations ${ }^{44}{ }^{45}$ that confirmed that there was an important benefit and in the process showed that resolution of pulmonary hypertension, the original theoretical reason for using domiciliary oxygen, did not explain all of the treatment success. Twenty years after these pioneering observations we again face a dilemma about a promising new treatment for chronic obstructive lung disease that only carefully conducted large scale prospective trials can resolve. These should be established soon.

P M A CALVERLEY

Consultant physician and senior clinical fellow,

Aintree Chest Centre,

Fazakerley Hospital,

Liverpool L9 $7 A L$

Reprint requests to Dr Calverley

1 Branthwaite MA. Assisted ventilation. 6-Non-invasive and domiciliary ventilation: positive pressure techniques. Thorax 1991;46:208-12.

2 Roussos CS, Macklem PT. Diaphragmatic fatigue in man. J Appl Physiol 1977;43:189-97.

3 Roussos C, Moxham J. Respiratory muscle fatigue. In: Roussos C, Macklem PT, eds. The thorax. Part B. Lung biology in health and disease. New York: Dekker, 1985:829-70.

4 Aldrich TK. Respiratory muscle fatigue. Clin Chest Med 1988;9:225-36.

5 National Heart, Lung and Blood Institute workshop summary. Respiratory muscle fatigue. Am Rev Respir Dis 1990;143:474-80.

6 Gross D, Grassino A, Ross WRD, Macklem PT. Electromyogram pattern of diaphragmatic fatigue. J Appl Physiol 1979;46:1-7.

7 Esau SA, Bellemare F, Grassino A, Permutt S, Roussos C, Pardy RL. Changes in relaxation rate with diaphragmatic fatigue in humans. J Appl Physiol 1983;54:1353-60.

8 Calverley PMA, La Porta D, Fleury B, Comptois A, Grassino A. Mouth occlusion pressure: a new test for inspiratory muscle fatigue [abstract]. Thorax 1984;39:716.

9 Moxham J, Morris AJR, Spiro SG, Edwards RHT, Green M. Contractile properties and fatigue of the diaphragm in man. Thorax 1981;36:164-8.

10 Bellemare F, Bigland-Ritchie B. Central components of diaphragmatic fatigue assessed by phrenic nerve stimulation. J Appl Physiol 1987; 63:1307-16.

11 Bellemare F, Grassino A. Effect of pressure and timing of contraction on human diaphragm fatigue. J Appl Physiol 1982;53:1190-5.

12 Bellemare F, Grassino A. Force reserve of the diaphragm in patients with chronic obstructive pulmonary disease. J Appl Physiol 1983;55:8-15.

13 Cohen CA, Zagelbaum G, Gross D, Roussos C, Macklem PT. Clinical manifestations of respiratory muscle fatigue. Am J Med 1982;73:308-16.

14 Tobin MJ, Perez W, Guenther SM, et al. Does rib cage-abdominal paradox signify respiratory muscle fatigue? J Appl Physiol 1987;63:851-60.

15 Gandevia SC, Killian KJ, Campbell EJM. The effect of respiratory muscle fatigue in respiratory sensations. Clin Sci 1981;60:463-6.

16 Bradley TD, Chartrand DA, Fitting JW, Killian KJ, Grassino A. The relation of inspiratory effort sensation to fatiguing patterns of the diaphragm. Am Rev Respir Dis 1986;134:1119-24.

17 Edwards RHT. Human muscle function and fatigue. In: Edwards RHT, ed. Human muscle fatigue: physiological mechanisms. London: Pitman Medical (Ciba Foundation Symposium 82) 1981:1-18.

18 Moxham J, Edwards RHT, Aubier M, et al. Changes in EMG power spectrum (high to low ratio) with force fatigue in humans. $J$ Appl Physiol 1982;53:1094-9.

19 Roussos C, Macklem PT. The respiratory muscles. N Engl J Med 1982;307: 786-97.

20 Juan G, Calverley PMA, Talamo C, et al. Effect of carbon dioxide on diaphragmatic function in human beings. $N$ Engl J Med 1984;310:874-9.

21 Wiers PWJ, Le Coultre R, Dallinga OT, et al. Cuirass respirator treatment of chronic respiratory failure in scoliotic patients. Thorax 1977;32:221-8.

22 Gavay ST, Turino GM, Goldring RM. Sustained reversal of chronic hypercapnia in patients with alveolar hypoventilation syndromes. $\mathrm{Am} \mathrm{J}$ Med 1981;70:269-74.

23 Sawicka EH, Branthwaite MA, Spencer GT. Respiratory fatigue after thoracoplasty: treatment by intermittent negative pressure ventilation. Thorax 1983;38:433-5.

24 Braun NMT, Marino WD. Effect of daily intermittent rest of respiratory muscles in patients with severe chronic airflow limitation (CAL). Chest 1984;85:593-605.

25 Cropp A, Dimarco AF. Effect of intermittent negative pressure ventilation on respiratory muscle function in patients with severe chronic obstructive pulmonary disease. Am Rev Respir Dis 1987;135:1056-61.

26 Gutierrez M, Beroiza T, Contreras G, et al. Weekly cuirass ventilation improves blood gases and inspiratory muscle strength in patients with chronic airflow limitation and hypercarbia. Am Rev Respir Dis 1988; 138:617-23

27 Zibrak JD, Hill NS, Federman EC, et al. Evaluation of intermittent long term negative pressure ventilation in patients with severe chronic obstructive lung disease. Am Rev Respir Dis 1988;138:1515-8.

28 Ambrosino N, Montagna T, Nava S, et al. Short term effect of intermitten negative pressure ventilation in chronic obstructive lung disease patients with respiratory failure. Eur Respir J 1990;3:502-8.

29 Scano G, Gigliotti F, Duranti R, et al. Changes in ventilatory muscle function with negative pressure ventilation in chronic obstructive lung disease. Chest 1990;97:322-7.

30 Celli B, Lee H, Criner G, et al. Controlled trial of external negative pressure ventilation in patients with severe chronic airflow limitation. Am Rev Respir Dis 1989;140:1251-6.

31 Shapiro SH, Macklem PT, Gray-Donald K, et al. A randomised clinical trial of negative pressure ventilation in severe chronic obstructive pulmonary disease; design and methods. J Clin Epidemiol 1991;44:483-96.

32 Levy RD, Carrey Z, Macklem PT, Martin JG. Suppression of ventilatory muscle activity in COPD patients with negative pressure ventilation. Am Rev Respir Dis 1988;137:A151.

33 Similowski T, Yan S, Gauthier AP, Macklem PT, Bellemare F. Contractile properties of the human diaphragm during chronic hyperinflation. $N$ Engl J Med 1991;325:917-23.

34 Levy RD, Bradley TD, Newman SL, Macklem PT, Martin JG. Negative pressure ventilation. Effects on ventilation during sleep in normal subjects. Chest 1989;95:95-9.

35 Ellis ER, Bye PIB, Bruderer JW, Sullivan CE. Treatment of respiratory failure during sleep in patients with neuromuscular disease. Am Rev Respir Dis 1987;135:148-52.

36 Smith PEM, Edwards RHT, Calverley PMA. Ventilation and breathing pattern during sleep in Duchenne muscular dystrophy. Chest 1989; 96:1346-51.

37 Carroll N, Branthwaite MA. Control of nocturnal hypoventilation by nasal intermittent positive pressure ventilation. Thorax 1988;43:349-53.

38 Elliott MW, Simonds AK, Carroll MP, Wedzicha JA, Branthwaite MA. Domiciliary nocturnal nasal intermittent positive pressure ventilation in hypercapnic respiratory failure due to chronic obstructive lung disease: effects on sleep and quality of life. Thorax 1992;47:342-8.

39 Elliott MW, Mulvey DA, Moxham J, Green M, Branthwaite MA Domiciliary nocturnal nasal intermittent positive pressure ventilation in COPD: mechanisms underlying changes in arterial blood gas tensions. Eur Respir J 1991;4:1044-52.

40 American Thoracic Society. Am Rev Respir Dis 1991;143: International Conference Supplement.

41 Calverley PMA, Brezinova V, Douglas NJ, Catterall JR, Flenley DC. The effect of oxygenation on sleep quality in chronic bronchitis and emphysema. Am Rev Respir Dis 1982;126:206-10.

42 Neff TA, Petty TL. Long term continuous oxygen therapy in chronic airways obstruction. Ann Intern Med 1970;72:621-6.

43 Leggett RJE, Cooke NJ, Clancy L, et al. Long-term domiciliary oxygen therapy in cor pulmonale complicating chronic bronchitis and emphysema. Thorax 1976;31:414-8.

44 Nocturnal Oxygen Therapy Trial Group. Continuous or nocturnal oxygen therapy in hypoxaemic chronic obstructive lung disease. Ann Intern Med 1980;93:391-8.

45 Medical Research Council Working Party. Long term domiciliary oxygen therapy in chronic hypoxic cor pulmonale complicating chronic bronchitis and emphysema. Lancet $1981 ; \mathrm{i}: 681-5$. 